RESEÑ

\title{
A la vuelta del tiempo. Modernidad y posmodernidad revisitadas
}

\author{
Michel Maffesoli, Le temps revient. Formes élémentaires de la \\ postmodernité. París: Desclée de Brouwer, 2010
}

\author{
MAGALY CABROLIÉ VARGAS \\ Universidad Católica de Temuco
}

Presentamos aquí ${ }^{1}$ un recorrido comentado de la obra de Michel Maffesoli Le temps revient. Formes élémentaires de la postmodernité, aparecida el año 20I0. En este trayecto hemos elegido ir de principio a fin siguiendo la estructura misma del libro, pero sin pretensión de exhaustividad dada su complejidad. Al mismo tiempo hacemos algunas observaciones en torno al estilo de escritura del autor y finalmente un comentario crítico sobre la obra.

Michel Maffesoli es profesor de sociología en la Universidad René Descartes, Sorbonne París V, y es considerado como uno, si no acaso el más importante, de los sociólogos de la llamada "posmodernidad».

El trabajo de Michel Maffesoli y sus ideas sobre la sociedad actual han sido publicados en numerosas obras, entre las más conocidas ${ }^{2}$ podemos mencionar en sus ediciones originales en francés: La violence totalitaire (I979),

I. Este trabajo fue redactado originalmente en francés y posteriormente traducido al español por la autora. De igual forma, todas las citas originales de los textos en francés fueron traducidas libremente por la autora.

2. Para acceder a una bibliografía completa de las obras de Michel Maffesoli, es posible ingresar a los sitios web <http://www.ceaq-sorbonne.org/node.php?id=9I > y $<$ http://www.michelmaffesoli.org/livres/>. 
Le temps des tribus (1988), La connaissance ordinaire (1985), Du nomadisme, vagabondages initiatiques (1997), Notes sur la postmodernité (2003), Le Réenchantement du Monde (2007). ${ }^{3}$ Maffesoli ha publicado también en numerosas revistas, especialmente en Sociétés (DeBoeck) y en Cahiers Européens de l'Imaginaire (CNRS), de las cuales él es su director.

Michel Maffesoli se reconoce profundamente marcado por el trabajo del antropólogo Gilbert Durand, quien fuera su profesor en la universidad de Grenoble y con quien él comparte la importancia de estudiar las estructuras imaginarias como fundamento de toda sociedad. Reconoce también la fuerte influencia en su trabajo de Emile Durkheim, Max Weber y de George Simmel, y se inscribe al mismo tiempo en la sociología fenomenológica.

El sociólogo francés Patrick Tacussel, en la obra dirigida por Jean-Michel Berthelot (2000), La sociologie française contemporaine, ubica a Michel Maffesoli en la que llama «sociología comprensiva de la vida cotidiana». Para Tacussel, «con el agotamiento del enfoque crítico según el cual la alienación es el factor central de la cotidianeidad (Henri Lefèbvre, Agnès Heller, Herbert Marcuse, Karel Kosik, Guy Debord...), otra postura, comprehensiva, se ha impuesto: metacrítica (Jean Baudrillard), formista (Michel Maffesoli) o figurativa (Pierre Sansot, Patrick Tacussel)»(Berthelot, 2000). Esta noción de formismo alrededor del pensamiento de Maffesoli hace referencia a una sociología que busca «evitar el fantasma del encierro, reconocer la singularidad, respetar el detalle y lo múltiple, hacer resaltar la aventura de lo cotidiano como una creación colectiva por 'aproximaciones sucesivas'» (Berthelot, 2000). Para alcanzar su propósito, Maffesoli hace converger, en su corpus teórico, por ejemplo la noción de tipo ideal de Weber, la de residuo de Vilfredo Pareto, de tipicalidad en Schütz, y el paradigma de la complejidad de Edgar Morin.

La obra a la que nos referiremos en las siguientes líneas consta de I 86 páginas, organizadas en ocho capítulos. Es un libro en el que su autor ha elegido ir directamente a su exposición, dejando de lado la redacción de una introducción y también la presentación de conclusiones.

En Le temps revient. Formes élémentaires de la postmodernité, Michel

3. Algunas ediciones en español: El tiempo de las tribus: el declive del individualismo en las sociedades de masa (Siglo xxI, México, 2004); El conocimiento ordinario: compendio de sociología (FCE, México, 1993); El nomadismo: vagabundeos iniciáticos (FCE, México, 2004); El reencantamiento del mundo. Una ética para nuestro tiempo (Dedalus, Buenos Aires, 2009). 
Maffesoli presenta algunos aspectos de su pensamiento en un conjunto sistemático de reflexiones que tienen por objetivo señalar claves de lectura y de comprensión de su itinerario teórico alrededor de las nuevas formas del estarjuntos propias de la sociedad contemporánea. De esta aspiración de clarificación sobre sus proposiciones da cuenta la paráfrasis del título del libro de Emile Durkheim Les formes élémentaires de la vie religieuse (I 9 I 2). El libro de Maffesoli tiene así un carácter más de ensayo que de investigación de campo, se trata de proposiciones que constituyen, cada una en un capítulo, de ocho formas de presentar su visión y su interpretación sobre los cambios que vive la sociedad actual y que vienen a constituir la posmodernidad.

Las ocho proposiciones de Maffesoli dan origen a los siguientes títulos, no fácilmente traducibles al español, por lo que hemos preferido mantenerlos aquí en su original en francés: L'enveloppementalisme postmoderne, La hauteur du quotidien, Climatologie, Le dessaisissement tribal, Invagination du sens, L'instinct nómade, Archaïsme et technologie, Imaginaire, imaginal.

El campo de estudio de Maffesoli son sus observaciones sobre el cotidiano de nuestra época donde se expresan nuevas formas de solidaridad (en referencia a Durkheim), tales como los modos de vida alternativos, el comercio justo, la moda, la tecnología y también el objeto de estudio más conocido del autor, las tribus urbanas. Todo aquello que Maffesoli considera como nuevas formas de socialidad y que responden a un imaginario que constituye, siguiendo su lectura, la fuerza del vínculo social.

En su argumentación, Maffesoli desarrolla la idea de que hoy estamos confrontados al regreso de formas arcaicas, tribales, de pertenencia, por oposición a una solidaridad orgánica propia de la modernidad, de aquí el nombre de su obra Le temps revient («el tiempo vuelve»), y también la importancia que él le da a la figura de la espiral, como metáfora de aquello que regresa, por oposición a una visión lineal de la historia. En un artículo precedente, Maffesoli había ya expresado que su método busca relevar aquello que tiene tendencia a volver en el tiempo:

mi método, que se ocupa de subrayar que nada es nuevo bajo el sol, y que en general aquello que se había olvidado tiende a volver al frente de la escena después de haber sido minimizado o negado (Maffesoli, 2008: 24).

Uno de los intereses de Maffesoli es desmitificar los ideales emancipadores y revolucionarios de la modernidad que habrían impuesto una especie de moral occidental del progreso. Para el autor hay también, en relación a ello, 
una cierta actitud de miedo, de no querer observar los cambios que se operan en la vida cotidiana, miedo que trae al conformismo: "Baste recordar que la necesidad de engañarse a sí mismo es el motor constante del conformismo de pensamiento» (20I0: I2). Su idea central, expresada en el primer capítulo «L'enveloppementalisme postmoderne», es afirmar que hay profundos cambios que necesitan de nuevas maneras de comprenderlos, porque las ya existentes no pueden hacerlo:

Un cambio de fondo está operándose. La matriz social moderna se revela más y más infecunda. La economía, los movimientos sociales, el imaginario, incluso la política sufren los embates de una marejada de la que no se ha terminado de medir la amplitud... Mutación societal que necesita una transmutación del lenguaje. Tal es la posmodernidad (Maffesoli, 2010: I3).

Maffesoli propone a partir de la afirmación anterior una nueva forma de comprehensión utilizando la noción de saturación del sociólogo P. Sorokin. En palabras de nuestro autor, la saturación corresponde a un "proceso casi químico que da cuenta de la desestructuración de un cuerpo dado, seguida de una reestructuración con los elementos mismos de aquello que ha sido deconstruido» (20IO: I4). Esta idea le permite decir que la modernidad ha sufrido un proceso de saturación que ha comenzado en los años cincuenta y que Maffesoli ejemplifica con los cambios que ha experimentado la arquitectura urbana con su mutación desde un estilo funcional hasta la complejidad y la ambigüedad bajo la forma de un mosaico o patchwork, característico de los espacios urbanos posmodernistas. Es a lo que el autor llama armonía conflictual (harmonie conflictuelle) y que está presente también en la socialidad posmoderna.

En su texto, el autor da un lugar especial a las dimensiones espacio y tiempo, porque es en ellas donde somos confrontados al otro y donde emergen los vínculos, lo que lleva a Maffesoli a afirmar que el lugar crea el vínculo (le lieu fait lien) (2010: 2I y 48). ${ }^{4}$ Lo anterior quiere decir que es en el espacio y el tiempo presentes que se forman las nuevas solidaridades, pertenencias e identi-

4. Hay que mencionar que esta idea es una de las predilectas de Maffesoli y que él la ha trabajado en varios de sus libros. Es interesante señalar que en más de una ocasión, en el curso de sus seminarios en La Sorbonne, él ha mencionado no conocer una fórmula tan precisa en español para expresar la misma idea: «le lieu fait lien». 
dades. «No es simplemente el tiempo el que es vector del estar-juntos, sino más bien el espacio como cimiento de la vida en común» (2I).

Para Maffesoli, a través de esta idea —el lugar crea el vínculo-, es posible acercarse a la comprensión de esas expresiones de la vida cotidiana de hoy, particularmente ciertas formas de localismo, por ejemplo: las celebraciones en torno al territorio, los productos típicos de cada terruño, los festivales folclóricos, las leyendas locales, y las puestas en escena de hechos históricos.

Volviendo a la idea de saturación y vinculándola con aquella de crisis de la modernidad, Maffesoli desarrolla su proposición en el segundo capítulo, «La altura de lo cotidiano», a partir de una hipótesis que él describe como:

La crisis económica (financiera) con que se nos tamborilean los oídos no es más que la forma última de la saturación de la idea de salvación individual (del plan de salvación). Y por lo mismo esta 'crisis' marca el regreso del ideal comunitario que de manera violenta (las revueltas lo testimonian) o bajo su forma más altruista (el voluntariado, las asociaciones, los modos de vida alternativos, el comercio justo, etcétera) busca nuevas formas de expresar la generosidad y la solidaridad propias del estar-juntos (52).

Para Maffesoli se trata de la necesidad de volver al fondo, que él llama preindividual y que es la vida cotidiana. El retoma aquí la idea de Max Weber sobre la importancia de «estar a la altura de lo cotidiano", lo que quiere decir considerar aquello que es no-racional, pero que tampoco es irracional, sino que tiene su propia lógica o significación. El autor, continuando con su argumentación sobre lo cotidiano, señala la importancia de «volver a una solidaridad orgánica», expresión durkheimiana que él utiliza para hacer referencia a la socialidad posmoderna donde se expresan las nuevas formas de encontrarse con los otros en la temporalidad del presente, compartiendo sentimientos y emociones que dan sentido de pertenencia.

La idea anterior remite a una cierta atmósfera, ambiente intramundano, clima, porque según el autor «estamos prendidos, de una sola pieza, en una constelación ambiental que hace de todos lo que cada uno es, y de lo que es muy difícil despegarse» (72). De aquí Maffesoli extrae el título de su capítulo «Climatología» para desarrollar su proposición sobre un cierto ambiente propio de la posmodernidad donde se encuentran los gestos, las variaciones lingüísticas, las vestimentas, las posturas corporales, la música y todo eso que hace el vivir juntos. 
El autor va a insistir sobre estos aspectos en los capítulos siguientes, pero agregando algunas variaciones, por ejemplo cuando caracteriza las solidaridades de lo cotidiano como un regreso a lo arcaico, a la tribu y sus rituales ( $« \mathrm{La}$ enajenación tribal»), y cuando él explica la lógica del regreso como «una vuelta al vientre, a los sentidos, a lo sensible [...] no más dejarse llevar por el flujo incesante del progreso y de su ideología» (IOI) a través de la metáfora de la invaginación del sentido. Con esta figura, Maffesoli puede hablar del regreso a formas de valorización del cuerpo, o corporeísmo, como la cosmética y la moda. Para él se trata del cambio de la «civilización domesticada, asegurada, que toca a su fin» para dar paso a la sensibilidad que conecta con la aceptación de la animalidad en la especie humana.

Michel Maffesoli va a poner el acento sobre la idea del regreso, hilo conductor de esta obra, en el capítulo llamado «El instinto nómada», como el arcaísmo inherente a las tribus y que él encuentra muy presente en la vida social contemporánea. El nomadismo toma formas — religiosas, culturales, económicas, etcétera-, y es portador de una paradoja entre lo dinámico y lo estático. Maffesoli llama a esta paradoja «enraizamiento dinámico».

En el capítulo sobre "Arcaísmos y tecnología», Maffesoli insiste sobre la idea del regreso. Para él, la modernidad ha sido dominada por el ideal del progreso y el desarrollo de la técnica, la tecnología y la tecnocracia, condición que él describe como «una vida social completamente aséptica por la 'violencia totalitaria' de una tecnocracia puramente racional [...] a todo lo largo del siglo $\mathrm{xx}$, el triunfo planetario de la técnica, es decir, la tecnificación del mundo» (I4O-I4I). La modernidad, según el autor, está confrontada hoy a una paradoja, porque es precisamente la tecnología la que permite expresar el regreso a lo lúdico, «ese lúdico que la modernidad, en su marcha real del progreso, había marginalizado» (I 43), y a las nuevas formas de estar vinculado (religado), por ejemplo, los chats, Facebook, Twitter, etcétera.

En esos 'chats', en efecto, lo importante es establecer el vínculo. El contenido poco importa. El continente lo es todo. Lo que está en juego es la 'atadura': estar ligado (del latín religare), estar en confianza (reliant en inglés). Es todo eso, y también otras cosas, las que me hacen decir que la tecnología posmoderna participa del reencantamiento del mundo (I42-I43).

Según el autor, lo anterior es posible porque hay dos características que son propias de nuestra especie: la capacidad de imaginar y la de entrar en comunión con el otro. 
Finalmente, Maffesoli va hasta el análisis de la preeminencia de la imagen hoy en día como expresión de aquello que él llama un cambio de paradigma, para llegar a aquel de "la ética de la estética», trabajando esta idea en el capítulo «Imaginario, imaginal». Según Maffesoli, la imagen «muestra eso que es y para lo que es y no para lo que debería ser» (I83). Es decir que en la sociedad contemporánea la imagen ocupa un lugar central en la mayor parte de las interacciones, especialmente en los procesos de comunicación a partir de medios tecnológicos, en los que la imagen no expresa más un estereotipo, sino exactamente aquello que la imagen muestra. Maffesoli utiliza la metáfora de la contaminación o de la viralidad para decir que el imaginario, la imagen posmoderna, circula para dar origen a nuevas formas de solidaridades muchas veces virtuales (como las redes sociales). Para terminar, Maffesoli dirá que hay que encontrar las "contraseñas» de la época para comprender el nuevo orden donde se conjugan «la razón y lo sensible, el intelecto y el afecto» (I 85 ). Esta última idea subraya que en la experiencia posmoderna ya no hay separación entre las diferentes dimensiones de la vida humana, sino que ellas se encuentran en lo cotidiano y se expresan en los vínculos que hacen las nuevas socialidades.

\section{Sobre el estilo de escritura del autor}

Michel Maffesoli es, en esta obra, ayudado por varios recursos de orden estilístico, pero que al mismo tiempo están profundamente ligados a la forma de construir su pensamiento. Por ejemplo, en el título de cada capítulo que acabamos de presentar más arriba, el autor anuncia el tema que va a desarrollar utilizando metáforas y proponiendo en algunos casos palabras que semejan más un juego lingüístico, pero cuyo objetivo es atrapar la atención del lector y dar una clave de lectura para llegar a comprender la hipótesis de esas nuevas expresiones de socialidad que constituyen las formas elementales de la posmodernidad. Esta manera de presentar su pensamiento se hace evidente al observar la ausencia de conceptos a través de su libro, a excepción de algunos conceptos, tomados de otros autores, con el propósito de transformarlos en el desarrollo de su argumento. Es el propio Maffesoli quien ha dicho que a él no le agradan los conceptos porque ellos son «cerrados», ${ }^{5}$ y que él prefiere hablar de nociones. Entre esas nociones hay algunas que tienen un lugar central

5. Michel Maffesoli, durante la presentación de su libro Le temps revient, el 28 de octubre de 20ıo, en la Fundación de la Empresa Ricard, en París. 
en esta obra, por ejemplo saturación (Sorokin), habitus (Tomás de Aquino y no Bourdieu), solidaridad orgánica (Durkheim), Dasein (Heidegger), sintonía (Schütz), entre otros, y particularmente las referencias a Weber.

Otro recurso que Maffesoli utiliza especialmente para presentar sus ideas y aclararlas es el lenguaje poético, lenguaje que vemos aparecer en varios pasajes de su libro, por ejemplo en aquel sobre la saturación o también en aquel sobre la invaginación:

Relación íntima y constante entre la parte destruida y la parte construida. Eso que se destruye y se reconstruye en todas las cosas. Vida y muerte ligadas en una mezcla estrecha e infinita ( ( 5 ).

La intensidad del momento, la exacerbación del cuerpo y del adorno, fuerza viva de los sentimientos, y así tantas manifestaciones de una eternidad, muy instantánea, que conviene gozar cuando ella se presenta (I I 7).

Maffesoli, además de las referencias de carácter filosófico, histórico, sociológico y literario, utiliza como recurso explicativo el análisis etimológico, sobre todo del latín, de sus palabras claves, lo que viene a constituir verdaderamente una característica a la vez de estilo, pero sobre todo de construcción de su reflexión.

En efecto, la palabra concreto, proviene de cum crescere, crecer con. La fenomenología nos ha aclarado sobre este 'con'. Se pueden declinar a placer las modalidades de tal relacionismo: estar-con los otros (mit Sein), con el mundo (mit Welt). Esto es lo que debería enviar a los osarios de los pensamientos muertos los análisis de esos sociólogos de serie 'B', así como los artículos periodísticos con que nos sirven la sopa, que continúan revolviéndonos el estómago con su pretendido 'individualismo contemporáneo' (29-30).

En la cita precedente podemos encontrar también otra característica de su trabajo que es la crítica a través de la ironía; por ejemplo, en el segundo capítulo a propósito de la emergencia de fenómenos de orden pagano como la deep ecology, el candomblé brasileño o la importancia de la astrología, Maffesoli agrega:

Y para estos últimos fenómenos en particular, es divertido ver que son sociólogos que se dicen cristianos quienes, montando en cólera, se abocan a criticarlos. ¿Es por temor a una competencia desleal? (45). 
En el texto es posible también encontrar referencias críticas a otros autores para expresar alguna idea en sentido opuesto, como en el caso de Bourdieu y el concepto de habitus. Maffesoli toma el concepto de habitus de santo Tomás de Aquino, y al mismo tiempo señala su distancia en relación a Bourdieu diciendo:

Es así que ciertos sociólogos, tales como Pierre Bourdieu, olvidando deliberadamente tales referencias, por temor tal vez a ser tachados de escolásticos, han, con fanfarronería, retomado el concepto para designar lo que son los comportamientos adquiridos, característicos de un grupo social específico (49).

Algo similar se puede señalar en relación a Alain Touraine. Cuando Maffesoli expone su hipótesis en torno a la crisis, él hace referencia, lo creemos posible, a la obra reciente de Touraine Après la crise, pero él no lo menciona por su nombre:

En efecto, hay los que se ocupan en arrinconar el "posmodernismo» al dominio artístico. Eso es no querer ver los hechos y los efectos posmodernos en la vida social. Aunque se empieza ya a susurrar que la crisis en curso no es simplemente económica, sino más bien 'societal' (I 7).

Cuando Maffesoli utiliza la ironía como forma de expresar una crítica, a veces cae también en la descalificación particularmente del mundo académico, como por ejemplo cuando él habla del temor que producen las mutaciones que se expresan en la sociedad contemporánea. Hace referencia a la relación entre miedo y conformismo, y retoma también en consecuencia el conformismo metodológico:

todo conformismo, teórico o existencial, reposa sobre el miedo. Conformismo metodológico y epistemológico resultado del miedo de estudiantes serviles a los pequeños mandarines universitarios ( ( 5 ).

Desgraciadamente se pueden encontrar numerosas referencias en la misma tesitura, como en esta última cita:

Estos aburridos predicadores que desde lo alto de sus cátedras universitarias o a través de sus tribunas mediáticas, se dedican a asustar a los tontos crédulos ( 142 ). 
El análisis de Maffesoli de lo que ocurre en nuestra sociedad ofrece una posibilidad de comprensión de los fenómenos que se observan en lo cotidiano que puede ser transversal a varias disciplinas, y no solamente a la sociología, y esa característica que puede ser un aspecto de fortaleza, puede ser también un aspecto de debilidad, desde otro punto de vista, considerando especialmente la ausencia de un itinerario metodológico para abordar los fenómenos de la vida cotidiana que él señala en su libro. La originalidad de su análisis atañe no sólo a sociólogos, sino también a antropólogos, psicólogos, semiólogos, filósofos, expertos en comunicación social, en arte contemporáneo, arquitectos, y en general a todo aquel interesado en los fenómenos de la vida cotidiana actual.

Si bien Maffesoli habla desde la sociología, su argumentación no puede avanzar sin recurrir a los aportes de la filosofía, la antropología, la historia y también de la literatura. Esta característica da cuenta de la gran amplitud de lecturas que van a alimentar su discurso y que él exhibe a través de su obra. Esta característica de diversidad, hace que la lectura de Le temps revient, sea muy grata y atractiva porque se puede pasar a través de numerosos autores (Rimbaud, Nietzsche, Blake, Baudelaire, Comte, Benjamin, Foucault, Pascal, Goethe, Kuhn; la lista puede ser muy larga), tradiciones teóricas, corrientes filosóficas, relatos mitológicos, y también a través de ejemplos muy próximos de la vida cotidiana contemporánea.

Todo ha sido escrito con elegancia y en un lenguaje muy cuidado y culto, pero sin embargo hay un aspecto que, en nuestra opinión, le resta parte de su valor a esta obra, y son las descalificaciones que Maffesoli dirige hacia otros miembros de su mundo académico más próximo. Cada vez que el autor utiliza dichas expresiones, la fluidez de la lectura es interrumpida por una especie de ruido que molesta y que no permite concentrarse verdaderamente sobre el propósito de orden más teórico del libro. Habría sido preferible, sin duda, que el autor mantuviera la misma tonalidad sabia a lo largo de toda la obra de manera de resaltar la dimensión teórica y la originalidad de su propuesta de análisis en torno de la socialidad postmoderna.

\section{Referencias}

Berthelot, J.-M. (2000). La sociologie française contemporaine. París: PUF Presses Universitaires de France. 
Maffesoli, M. (2008). "L'objet subjectif et l'ampleur des relations symboliques». Sociétés, 3 (IоI): 23-3 I.

-. (2010). Le temps revient. Formes élémentaires de la postmodernité. París: Desclée de Brouwer.

Touraine, A. (2010), Après la crise. París: Éditions du Seuil.

\section{Sobre la autora}

Magaly Cabriolé Vargas es docente de la Universidad Católica de Temuco; doctora en Estudios Latinoamericanos, UnAM, México; magister en Ciencias Sociales, Flacso México y asistente social, Pontificia Universidad Católica de Chile. Su correo electrónico es <mcabrolie@uct.cl>. 